\title{
ADDRESSING THE MAJOR INFORMATION TECHNOLOGY CHALLENGES OF ELECTRONIC TEXTBOOKS
}

\author{
HeeJeong Jasmine Lee* \\ School of Information Technology, Monash University \\ Victoria 3800 Australia \\ Telephone: + 61399026011 \\ Kok-Lim Alvin Yau \\ Faculty of Science and Technology, Sunway University
}

No. 5, Jalan Universiti, Bandar Sunway, 47500 Subang Jaya, Selangor Malaysia

Telephone: +60 374918622

Fax: +6 0356358633

heejeong.lee@monash.edu, koklimy@sunway.edu.my 


\title{
ADDRESSING THE MAJOR INFORMATION TECHNOLOGY CHALLENGES OF ELECTRONIC TEXTBOOKS
}

HeeJeong Jasmine Lee

\author{
Kok-Lim Alvin Yau
}

\begin{abstract}
Electronic textbooks (e-Textbooks) are digitized forms of textbooks which are envisioned to replace existing paper-based textbooks. After intensive literature review, together with interview results, our study has figured out four major IT-based challenges associated with e-Textbooks in its pursuit to replace the traditional textbooks, namely standardizing format of content, improving service reliability, improving quality and accuracy of content, and improving readability. This paper also provides an extensive review on how these challenges have been approached using existing e-Textbook solutions, such as $N$ Screen services, cloud computing, open market place, P2P between devices and HTML5. For each solution, we develop a usage scenario in which users apply the aforementioned technologies to interact with e-Textbooks and share contents among themselves. This article aims to provide a strong foundation for further investigations into the development and distribution of e-Textbooks for eventual successful adoption of e-Textbooks in school education.
\end{abstract}

Keywords: electronic textbook, e-Textbook, digital textbook, ICT in education, IT strategies and development of e-textbooks

\section{INTRODUCTION}

Electronic textbooks (e-Textbooks) or digital textbooks are digitized forms of textbooks that could potentially replace existing paper-based textbooks in the school curriculum. Compared to traditional textbooks, four main advantages of e-Textbooks have been reported in the literature $[2,5,37]$. Firstly, the incorporation of multimedia contents, such as video clips, animations and education-based games, are some of the elements of eTextbooks that have been shown to capture students' interest in study. Secondly, students are no longer carrying backpacks loaded with heavy textbooks to schools. Thirdly, eTextbooks enable easy backup and replacement so that any losses can be easily replaced by new copies from e-Textbook servers. Fourthly, fast update and access to the latest content are possible.

E-Textbooks have been envisioned to be a preferred and common choice of teaching and learning tool in the very near future. Recently, schools in the UK, USA and Australia have conducted pilot testing using devices such as Apple ${ }^{\circledR}$ 's iPad and Amazon ${ }^{\circledR}$ 's Kindle ${ }^{\circledR}$ to convert the content of paper-based textbooks to e-Textbooks $[20,45]$. While eTextbooks are seen as promising, its introduction to classrooms at the national level is 
seen as a major challenge. A wide range of problems and issues associated with e-Textbooks from various perspectives, such as curriculum, pedagogy, assessment and infrastructure, must be addressed.

While there are numerous reports and studies on e-learning $[23,3,16]$ and the advantages of e-Textbooks [2, 5, 37], a technical review that provides an extensive discussion on the challenges, as well as important technologies for the development and distribution of e-Textbooks, is notably absent; and so this is the focus of this article.

This research applies expert interviews [9], which have been widely applied to seek opinions from experts in regard to IT-related issues, to propose potential solutions for eTextbooks implementation in order to overcome the challenges $=$. The research outcome of this study provides important recommendations on new features to be incorporated into e-Textbooks and their distribution systems. This article also serves as a foundation for further investigations in this emerging research area.

The remainder of this article is organized as follows. The next section presents research questions, followed by research methodology. The challenges of e-Textbooks will then be presented, followed by a comprehensive strategy framework to overcome problems and issues associated with e-Textbook usage. Lastly, the conclusions and future work are presented.

\section{RESEARCH QUESTIONS}

An e-Textbook is a package consisting of teaching and learning contents in electronic format and the computer devices used to access the contents [36, 44].

This research aims to explore a research question pertaining to the successful adoption of e-Textbooks in school education. In our previous research [27], we have figured out eight challenges, namely providing lower price, standardizing format of content, improving service reliability, improving quality and accuracy of content, increasing life of ownership, reducing health risk and visual fatigue, improving readability, and protecting copyright. Among the eight challenges, this paper further provides an extensive review on four challenges (i.e. improving quality and accuracy of content, im-proving readability, standardizing format of content and improving service reliability), and focuses on how these challenges have been approached using existing e-Textbook technologies. The four challenges have been chosen due to their importance based on the outcomes of our expert interviews. In short, our research question is "What are the technological solutions to the four challenges which are relevant to the development and distribution of e-Textbooks?"

The following limitations and assumptions apply to this study:

- Researchers $[28,50]$ have carried out case studies on the usefulness of e-Textbooks and their impact on learning. They have found that e-Textbooks have the potential to address some of the shortcomings of paper-based textbooks. Although investigating the effects of e-Textbooks is an important research topic, our study focuses on the challenges of e-Textbooks and the respective technological solutions to the challenges. Further investigations could be pursued to examine the values of using e-Textbooks in lessons and the associated pedagogical issues pertaining to teaching and learning, as well as the features and relative merits of different types of e-Textbooks.

- For the purpose of this study, we have identified eight categories of challenges in 
our previous research [27]. Hence, generalisations (e.g. reliability and validity) for the eight categories are not included in this paper.

\section{METHODOLOGY}

This research involves an extensive literature review, as well as expert interviews, to gather and identify the key technologies associated with the introduction of e-Textbooks in classroom. The technological solutions address the challenges associated with standardizing format, improving service reliability, improving quality and accuracy of content, as well as improving readability. The literature is derived from various sources including IEEE Xplore [18], the ACM Online Library [1] and ScienceDirect [12]. The rest of this Section presents our prototype, which has been applied during expert interviews in this study, and three main steps as part of our research methodology, namely problem analysis (which is based on previous research), the selection of challenges, as well as technology reviews and suggestions for the integration of these technologies into e-Textbooks.

\section{Prototype Development}

There are three categorizes of e-Textbooks, namely web-based content, reading software/application, and dedicated device [26]. Generally speaking, different categories of e-Textbooks use different underlying devices (e.g. hardware and software) to access eTextbooks. The content may require specific hardware devices (e.g. tablets, hand-held devices and PCs) for displaying and reading.

We have developed a web-based prototype of e-Textbooks with users' familiarity to paper-based textbooks in mind. Hence, our e-Textbook retain the advantages of the traditional paper-based textbooks, while adding new features and functions such as video clips, animations and links to the content. Specifically, our e-Textbook retains the features and functions of paper-based textbooks such as a table of content, page view and writing on textbook pages, and most importantly, interactive multimedia materials. The content is based on a current mathematics textbook [25].

Our e-Textbook prototype can be accessed via a web browser through wired or wireless networks. Users can access e-Textbooks through PCs (see Figure 1), tablets or smart phones (see Figure 2) etc. A user with internet access can upload/download content to/from the server; and once the content is downloaded to the prototype, users can access it offline.

Our prototype has been tested and revised during a series of Information Technology (IT) competitions; hence, this article provides a time-tested and practical guideline to design e-Textbooks. The prototype has won a merit prize for being the best concept and product in the e-learning category at a national-level competition called APICTA'11 [33] and it has also won a gold award at ITEX'12 [21]. Our prototype is not a commercial product; however it allows realistic and pragmatic evaluations of many concepts in eTextbooks. 


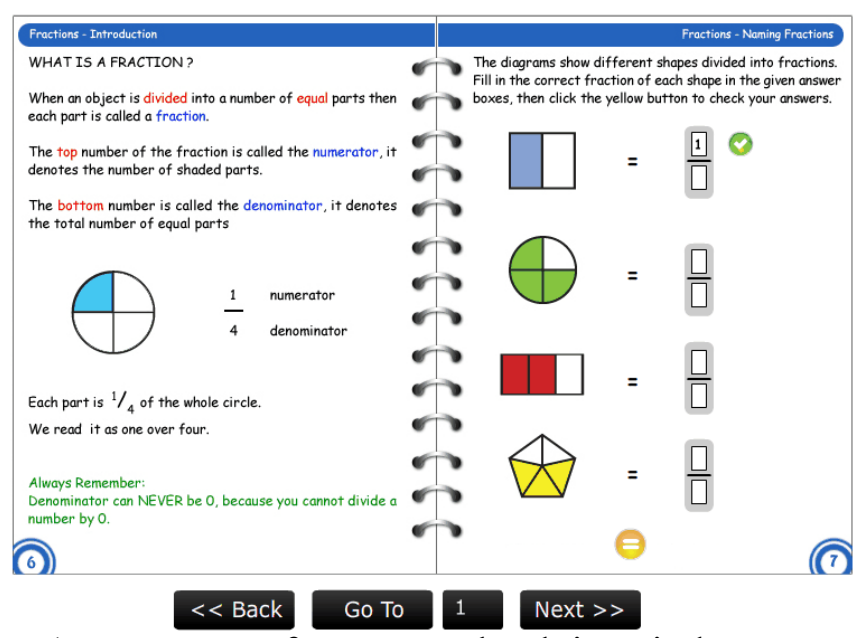

FIGURE 1. Prototype of our e-Textbook in Windows ${ }^{\circledR}$ PC.
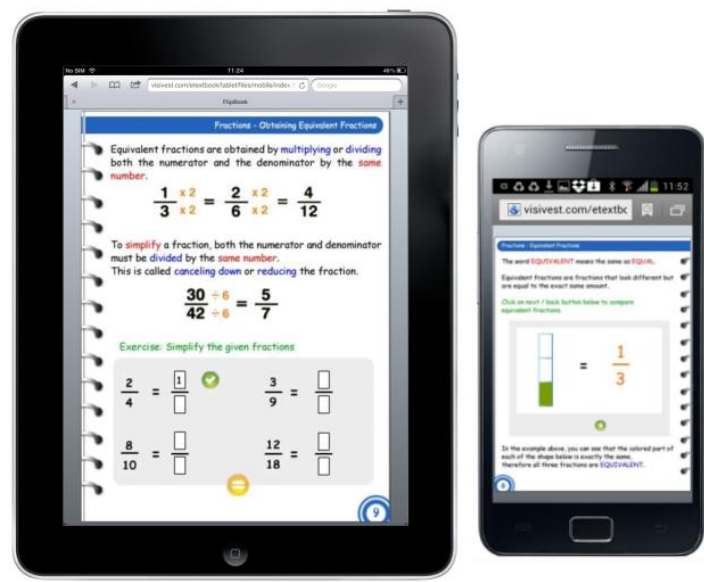

FIGURE 2. Prototype of our e-Textbook in $\mathrm{iPad} \AA$ and smart phone.

Generally speaking, different devices (e.g. PC, smart phone) use different hardware components (e.g. keyboard, monitor, data storage, CPU); therefore, their software and applications have to be developed using different software architectures (e.g. object-oriented, service-oriented) and programming languages (e.g. Java, Objective-C) [11]. For example, in order to allow users to run e-Textbooks in multiple execution environments (e.g. Windows, iOS, Android, BlackBerry and Symbian OS), applications developed in one platform (e.g. iOS) should be transformed into another form which can be used in other devices. Figure 3 summarises the different software or applications in each the different platform environments. 


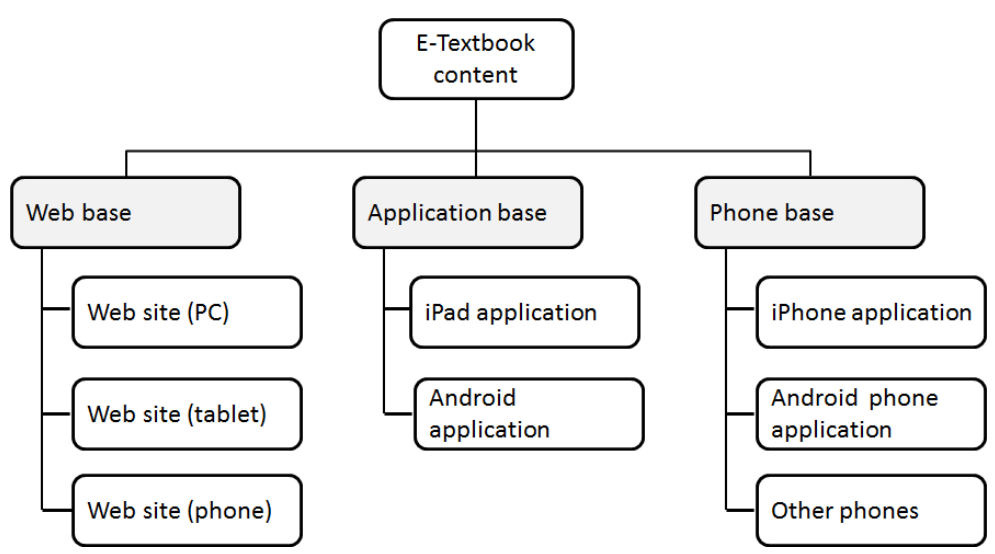

FIGURE 3. Taxonomy of different applications for different environment.

\section{Research Procedure}

In the first step, we performed problem analysis through literature review. Subsequently, we interviewed academic staff and students in order to identify the key challenges and problems pertaining to the successful adoption of e-Textbooks. Eight important key challenges were identified based on the eight challenges found in the previous research. The eight challenges are providing lower price, standardising format of contents, improving service reliability, improving quality and accuracy of content, increasing life of ownership, reducing health risk and visual fatigue, improving readability, and protecting copyright. The objective of the interview was to understand the perceptions of students and academic staff on the challenges of e-Textbooks in order to reinforce the key challenges and problems identified in the literature review. During the interview, firstly, a hands-on short tutorial was given to the respondents, and the tutorial covers an explanation on how e-Textbooks differ from e-books.

In the second step, for the purpose of this study, four areas of IT-related challenges namely standardising format of contents, improving service reliability, improving quality and accuracy of content, as well as improving readability, have been selected among eight challenges due to their importance based on the outcomes of the expert interveiw. In order to address these four challenges, ten (10) IT lecturers at universities and thirteen (13) industry experts from South Korea and Malaysia were interviewed. The following section presents the data analysis of the outcomes of the interview.

In the third step, the key technologies to address the four major challenges were identified through literature review and interview. An extensive assessment on the evolving technology was performed in order to understand how the key challenges and problems identified in the interviews have been approached using state-of-the-art technologies.

\section{Data Analysis of Interview Outcomes}

In this section, the interview results on the importance of the challenges are presented. To indicate the relative importance of the IT based challenges, the mean values of scores $s$ are categorized based on Likert format as shown in Table 1. In Table 1, the importance or significance of a particular challenge is categorized into five ranges, and it is rated from not important $(s \leq 1.0)$ to extremely important $(4.0<s \leq 5.0)$. 
TABLE 1 .

Importance of challenges based on the Likert format

\begin{tabular}{l|l}
\hline \hline \multicolumn{1}{c|}{ Score } & \multicolumn{1}{c}{ Description } \\
\hline $4.0<s \leq 5.0$ & Extremely important \\
\hline $3.0<s \leq 4.0$ & Very important \\
\hline $2.0<s \leq 3.0$ & Moderately important \\
\hline $1.0<s \leq 2.0$ & Slightly important \\
\hline$s \leq 1.0$ & Not important \\
\hline \hline
\end{tabular}

Table 2 shows the mean and standard deviation of the score values $s$ for each type of challenge. Higher standard deviation indicates that the data collected spread apart from the mean value. An analysis of the results indicates that respondents

- rated improving quality and accuracy of content, as well as improving readability, as extremely important.

- rated improving quality and accuracy of content achieve the highest score (extremely important) among these eight challenges.

- rated the other six challenges as very important.

TABLE 2.

A summary of IT-related challenges

\begin{tabular}{l|c|c}
\hline \multicolumn{1}{c|}{ Challenges } & $\mathrm{M}$ & $\mathrm{SD}$ \\
\hline Providing lower price & 3.52 & 1.47 \\
\hline Standardizing format of content & 3.96 & 0.88 \\
\hline Improving service reliability & 3.96 & 0.98 \\
\hline Improving quality and accuracy of content & 4.43 & 1.04 \\
\hline Increasing life of ownership & 3.35 & 1.03 \\
\hline Reducing health risk and visual fatigue & 3.83 & 1.03 \\
\hline Improving readability & 4.35 & 0.78 \\
\hline Protecting copyright & 3.48 & 1.31 \\
\hline \hline
\end{tabular}

\section{CHALLENGES}

This section summarizes the four major IT-related challenges associated with e-Textbooks which have been dicusses in the literature [28]. The respective technological solutions are presented in the next section.

\section{Improving Quality and Accuracy of Content}

Changes to paper-based textbooks have fewer issues with quality and accuracy because they have to go through several processes, particularly the review process which may involve several revisions being produced, before changes are confirmed. However, as "digital content are easily created, edited and delivered online" [27], the content must be accurate and its quality must be assured to ensure that the changes are appropriate and can be adapted to the national school curriculum.

\section{Improving Readability}

There have been concerns about the perceived difficulties in reading electronic media [27]. Students have been found to be reluctant to use e-Textbooks because the legibility of the text is inferior to the traditional paper-based textbooks [25]. Additionally, browsing 
and reading are much easier with paper-based textbooks.

\section{Standardising Format of Contents}

Compatibility is the ability of an application to run on different computers or different platforms without changing its format [10]. With the inclusion of multimedia contents and interactivity, an e-Textbook may need to support various types of formats. Additionally, different schools may use different formats. Hence, a student who uses a particular hardware or software may not be able to access contents from other service providers or other schools.

The issue of incompatibility between e-Textbook software and hardware (e.g. reading device) $[8,42]$ is of significant, and it was found that "the format war for e-Textbooks is a hurdle that must be overcome" [27]. Research [27] shows that e-Textbooks must be highly compatible.

\section{Improving Service Reliability}

Service reliability requires three conditions [43]. Firstly, service should be available "when the customer wants to use it". Secondly, customer has continuous service"over desired duration". Thirdly, service "meets the customers' expectations". When e-Textbook service does not meet the above three conditions, students may not be able to access the learning contents when necessary. Research [27] shows that e-Textbooks must be highly reliable.

\section{THE PROPOSED TECHNOLOGICAL SOLUTIONS}

This section addresses our research question: What are the technological solutions to the four challenges relevant to the development and distribution of e-Textbooks? Fundamental technologies of e-Textbooks are driven by various factors, such as the demand for new technology, their potential market value, and the complexity of the new technology [31]. Selecting the right technology for each component is an on-going challenge to the successful development and implementation of e-Textbooks in classrooms. This section addresses the challenges identified in the previous section by adopting the latest e-Textbook technologies suggested during expert interview. Literature review has been conducted to reinforce the solutions identified during the interview. Table 3 shows how the challenges of e-Textbooks have been approached using various technological solutions.

TABLE 3.

The challenges of introducing e-Textbooks and their respective technological solutions

\begin{tabular}{|c|c|}
\hline Challenge & Technological Solution \\
\hline $\begin{array}{l}\text { Improving Quality and Accuracy } \\
\text { of Content }\end{array}$ & $\begin{array}{l}\text { - Cloud computing } \\
\text { - Open Market Place }\end{array}$ \\
\hline Improving Readability & $\begin{array}{l}\text { - User-friendly system (e.g. proper } \\
\text { choice of font, color, size, as well } \\
\text { as zooming function) } \\
\text { - Screen-related technology }\end{array}$ \\
\hline $\begin{array}{l}\text { Standardising Format of Con- } \\
\text { tents }\end{array}$ & $\begin{array}{l}\text { - N-Screen services } \\
\text { - HTML5 }\end{array}$ \\
\hline Improving Service Reliability & $\begin{array}{l}\text { - Cloud computing } \\
\text { - Open Market Place } \\
\text { - P2P between screens }\end{array}$ \\
\hline
\end{tabular}


Screen-related technologies (see Table 3), such as electronic paper, have been extensively discussed in [27]; and so in the following subsections, more in-depth discussions will be focused on cloud computing, Open Market Place, N-Screen services, HTML5 and P2P between devices. For each solution, we develop a usage scenario in which people use the aforementioned technologies to interact with e-Textbook and share contents among themselves.

\section{Cloud Computing}

This section presents an overview of cloud computing, how cloud computing has been integrated into the prototype, as well as how this technology has been adopted to address the challenges of improving quality and accuracy of content and improving service reliability.

\section{Technological Overview}

Cloud computing is defined as "a model for enabling ubiquitous, convenient, on-demand network access to a shared pool of configurable computing resources (e.g., networks, servers, storage, applications, and services)." [35]. "Cloud computing provides on-demand delivery of information services whereby shared resources, software, and information are delivered as a utility over a network" [27]. Hence, "cloud technology is essential to the N-Screen platform for service synchronization on multi-devices" [40]. The $\mathrm{N}$-Screen platform will be presented later in this section. Without cloud computing, students must access to network drives at schools. However, using cloud computing, sharing and storing learning content in the cloud is possible.

Two types of cloud solutions are suggested for the school environment [7]. One type is the web-based application in which applications are delivered as a cloud service after login. Examples are Google Apps [15] or Office 365 [32]. Students can access web-based apps (e.g. a word processing, presentation, spreadsheet, and drawing applications) via a browser while they have their own desktop and applications on their devices. Sharing of documents with other students is possible [17]. The advantage of this model is that it facilitates collaboration among students, particularly in group projects. The other type is widely called the virtual desktop model in which applications, as well as desktops, are delivered as a cloud service after login into server. This cloud solution may be customized, and so every student can have the same kinds of desktops and applications to facilitate a common environment within an organisation. The advantage of this model is that, in addition to sharing of documents, it provides sharing of computing facilities since the server serves as a point of process. Similar concept has been applied to thin clients [7].

The benefits of these two cloud models are that students and teachers can have all of their apps and content [7] from the cloud.

\section{Integration of Cloud Computing into Prototype}

Cloud computing can be applied to allow users to download e-Textbooks. For instance, cloud architecture such as web-based application allows users to login into a cloud service, and subsequently use it to access e-textbooks. By keeping e-Textbook contents in the cloud, which is a centralized data storage area, the quality and accuracy of the content can be improved because corrections on the e-Textbook contents can be easily as content 
providers need only to modify and revise the contents in the centralized areas. In this work, we requested the interviewees about their opinions on how cloud computing can be applied to improve quality and accuracy of content, as well as service reliability. In our future work, cloud computing will be incorporated into our prototype to verify this.

Addressing the Challenge of Improving Service Reliability and Improving Quality and Accuracy of Content

The delivery mechanism of e-Textbooks can be integrated into a cloud architecture in order to achieve three main advantages [39]: virtualisation, centralized data storage, and monitoring of data access. Virtualisation enables users to access content remotely. Additionally, virtualisation reduces the number of servers required to maintain e-Textbooks, and so the maintenance cost of servers can be minimised. Centralized data storage enables users to retrieve e-Textbooks easily from the cloud, and this improves service reliability because users may have less worry about losing a textbook. Since cloud computing provides an entry point to all shared resources, monitoring data access becomes easier because it is not necessary to monitor all e-Textbook servers. For example, a teacher can monitor students' performance and keep track of the frequency of access to e-Textbooks through cloud computing remotely.

Through cloud computing, students do not need to synchronize data from one device to another. This means that the cloud synchronizes data from different devices or from different clouds. E-Textbooks enable easy backup and replacement so that any losses can be easily replaced by new copies from e-Textbook servers. Additionally, fast update and access to the latest content are possible. Hence, cloud computing can be a potential solution for e-Textbook implementation to overcome the challenges of improving service reliability and improving quality and accuracy of content.

Selected comments received from the expert interview as as follows:

- Using multiple redundant sites, cloud computing can help to maximize the reliability of e-Textbook services. [Expert 3]

- Cloud computing service providers have the latest technologies (e.g. firewalls, data centers) compared to individual users. [Expert 8]

- Companies using cloud services are more efficient at getting their services back to normal during service breakdown than those using their own servers. [Expert 11]

The cloud server provides a collection of knowledge for students. Tailor-made content can be uploaded to the cloud server and can be shared among users. In order to enrich the content, various book publishers and content providers upload their content into the cloud database or open market place, which will be presented shortly, . In this way, users can access the database at anytime and anywhere using any devices. Also, it ensures that the database is being kept up-to-date; hence, it provides up-to-date contents to users. In this way, the quality and accuracy of the content are ensured because users can retrieve up-to-date contents from the cloud.

Selected comments received from the expert interview as as follows:

- The qualtify of contents can be improved through collaborative effort using cloud. [Expert 8]

- Cloud computing can provide accurate, consistent and complete contents. [Expert 


\section{Open Market Place}

This section presents an overview of open market place, how open market place has been integrated into the prototype, as well as how this technology has been adopted to address the challenges of improving service reliability and improving quality and accuracy of content.

\section{Technological Overview}

Compared to the legacy of sole provider model, new emerging products, such as iPad $\mathbb{}$ and Android ${ }^{\mathrm{TM}}$ tablet, provide an ecosystem consisting of dynamic app developers who support these platforms through open market place. In the case of Android ${ }^{\mathrm{TM}}$ devices, manufacturers compete amongst themselves to provide up-to-date devices. Also, the reliability of after-sales services are provided through the manufacturer's network and therefore customers are not restricted to a particular manufacturer or service.

\section{Integration of Open Market Place into Prototype}

Similar to cloud computing, open market place can be applied to allow users to download e-Textbooks. Similarly, by keeping e-Textbook contents in the open market place, which is a centralized data storage area, the quality and accuracy of the content can be improved. Open market place also provides service reliability which helps to retrieve e-Textbook contents from a centralized data storage area. This means that users may have less worry about losing a textbook. In this work, we requested the interviewees about their opinions on how open market place can be applied to improve quality and accuracy of content, as well as service reliability. In our future work, open market place will be incorporated into our prototype to verify this.

Addressing the Challenge of Improving Service Reliability and Improving Quality and Accuracy of Content

Open market concept can be used for the delivery of e-Textbooks. Even though the Content Providers (CPs) may not have their own servers, they can distribute their contents easily through open market place such as app stores.

As open market place can increase transactions between CPs and users [40], fast update and access to the latest content are possible which can lead to the improvement of the quality and accuracy of content. Also, this helps CPs to monetize their services and secure CPs resource [4]. Hence, open market place can be potential solution for e-Textbooks implementation to overcome the challenge of improving service reliability and improving quality and accuracy of content.

Selected comments received from the expert interview are as follows:

- It is possible to obtain information via open market, but the information must be monitored by experts in order to improve the accuracy of contents. [Expert 4]

- Open market can provide fast updates of contents. [Expert 10]

\section{N-Screen Service / Multi-Device Service}

This section presents an overview of N-Screen and multi-device services, how N-Screen and multi-device services have been integrated into the prototype, as well as how these services have been adopted to address the challenge of standardising format of contents. 


\section{Technological Overview}

According to the screen study by Google, "it turns out that 90 percent of people move between devices to accomplish a task" [24]. In other words, users are likely to spread out their tasks between multiple devices. For example, users use the smartphone to gather information, to check emails and to browse social networking; and in many cases, the tasks will be transferred to PCs or tablets and continued there.

$\mathrm{N}$-Screen service (or Multi-Device service) has as its objective "to provide the same content or services on a variety of devices" [40]. Examples of devices are PCs, tablets, smartphones, netbooks, smart TVs, Portable media player (or more widely known as PMP), eBook readers, Internet TVs etc. [4]. While the internet service has been focused on "the supplier's point of view with One Source, Multi Channel in mind", N-Screen service focuses on "the continuity of services for the convenience of consumers, which can be described as One User, Multi Device"[40]. The core element of N-Screen service is a platform that allows the use of services on a variety of devices possible [49].

Based on a forecast conducted by IMS Research [19], we will have " 22 billion Internet-connected devices by 2020". In view of this, enabling multi-device services has been "gaining attention for enabling users to enjoy the same content or services seamlessly, irrespective of which device / medium is used" [4]. In other words, it is necessary to provide seamless service across several devices so that one can access the same content using various devices. In general, the interface for synchronization and replay between service providers and applications are essential [4]. This means that the underlying software and applications must seamlessly adapt to various formats. This helps users to use internet-enabled devices anytime and anywhere using any devices.

\section{Integration of N-Screen Service/Multi-Device Service into Prototype}

$\mathrm{N}-\mathrm{Screen}$ service (or multi-device service) has been incorporated into our prototype. For instance, our e-Textbooks can be accessed using various devices including PCs, tablets and smart phones as described in our prototype development. In this work, the interviewees were asked to rate the importance of, as well as their opinion on how N-Screen service has contributed towards, standardising format of contents while using the prototype.

\section{Addressing the Challenge of Standarising Format of Content}

Due to a wide range of formats of contents and service platforms, defining a standard format for the purpose of e-Textbook interoperability may be a complex and distant goal. Hence, N-Screen service should be able to read various formats, such as PDF, ePub, txt and html. Additionally, reader applications offered by N-Screen service should be able to convert various formats to more popular formats which are available in various online markets at no cost (e.g. free open source systems) or for a reasonable price; and schools can encourage students to download them.

As an example of e-Textbook usage, teachers can transmit live lessons or quizzes to students' computers or tablets in schools, and students can respond and answer the quizzes using their own devices at home. Students are no longer carrying paper-based textbooks to schools. However, if governments do not allocate sufficient budget to support devices to every student, "Bring Your Own Device (BYOD)" policy can be applied to 
achieve national goals of Information and Communications Technology (ICT) in education. This policy allows students to bring "a personally owned device for use and connectivity on an institutional network" [13]. However, some students may not be able to afford the device. Hence, when implementing this model, governments "need to develop a financial aid program that may include grants, scholarships and rental programs" [7].

Another issue is that students may not have the same applications if they use N-Screen service. This can be solved using aforementioned two types of cloud solutions.

Selected comments received from the expert interview are as follows:

- Using standard/general tools like web-based solutions allow applications to be used in many devices. [Expert 4]

- Standardising format of contents involves participation from providers or vendors of different platforms and devices. [Expert 9]

\section{HTML5}

This section presents an overview of HTML5, how HTML5 has been integrated into the prototype, as well as how this technology has been adopted to address the challenge of standardising format of contents.

\section{Technological Overview}

"New open standards created in the mobile era, such as HTML5, will win on mobile devices (and PCs too)" - Steve Jobs [22].

There are two types of mobile applications, namely native mobile application and mobile web application, for mobile devices including smart phones, $\mathrm{iPad}{ }^{\circledR}$ and Android ${ }^{\mathrm{TM}}$ tablets. For native mobile applications, users are required to download these applications through an online store or marketplace such as Apple ${ }^{\circledR}$ App Store and Android ${ }^{\mathrm{TM}}$ applications available in Google Play, and subsequently to install them on their respective mobile devices. On the other hand, for mobile web applications, users can access the application through the web browsers of their respective mobile devices (i.e. Safari on iPhone), and so it is not necessary to download and install these applications on devices [34].

Because of the need of installation, compatibility of the native mobile application on different platforms may be an issue, and so the development of e-Textbook content or reading software must be conducted for each platform in order to support as many devices as possible. Most importantly, in the absence of code conversion, iPad and iPhone applications cannot run on Android devices. This implies that, using N-Screen service, application developers may experience difficulties in developing different versions for distinctive devices.

HTML5 enables cross platform and cross device. Without the need to convert the format of an application, cross platform enables users to switch from one platform (e.g. Windows and Java platforms) to another [46], and cross device enables users to switch from one device (e.g. smartphones, laptops, tablets, and desktops) to another. Hence, it is a powerful tool to build cross-platform apps using well-known existing development tools (e.g. HTML, CSS, and JavaScript); and developers are not required to relearn new programming languages [15]. The latest version of major browsers (e.g. Chrome 21, Firefox 15, Opera 11.61) on PCs, smartphones and tablets runs HTML5 which allows developers to write code that can run on different operating systems and devices. 


\section{Integration of HTML5 into Prototype}

HTML5 has been incorporated into our prototype. Our e-Textbook, which is a web-based prototype, was developed using HTML5. In this work, the interviewees were asked to rate the importance of, as well as their opinion on how HTML5 has contributed towards, standardising format of contents while using the prototype.

\section{Addressing the Challenge of Standarising Format of Contents}

HTML5 uses fluid layout, in which the webpage can be adjusted according to user requirement including resolution and website layout, and responsive web design in which developers can develop multiple applications using a single source code that run on any screen size. Hence, HTML5 is a potential solution for e-Textbooks implementation to overcome the challenge of standardising format of contents. However, HTML5 is yet ready for e-Textbook development because of issues such as browser compatibility which are yet to fully support HTML5 and the lack of development tools such as Adobe Flash. For example, to create animations using HTML5, CSS and JavaScript developers must write codes instead of drawing using Adobe Flash, which is a common practice. Hence, further efforts are necessary to improve the features of HTML5, including the incorporation of design features from third-party, file uploads, local file storage, and offline support using cache.

Selected comments received from the expert interview are as follows:

- Use standardized language such as HTML5 helps to overcome the challenges in regard to standardisation. [Expert 2]

- Standardising format of contents is infeasible given the presence of a few main market players, each using their own format. However, with HTML5, standardising format of contents is feasible. [Expert 3]

- XML and HTML5 help to standardise the format of contents. [Expert 10]

\section{P2P between devices}

This section presents an overview of P2P between devices, how P2P has been integrated into the prototype, as well as how this technology can be adopted to address the challenge of improving service reliability.

\section{Technological Overview}

Apple ${ }^{\circledR}$ 's sample textbook has a size of up to $1 \mathrm{~GB}$. It needs a lot of storage to save these textbooks. However Apple ${ }^{\circledR}$ 's iPad $\AA$ has $16 \mathrm{~GB}, 32 \mathrm{~GB}$ and $64 \mathrm{~GB}$ storage only. To access many textbooks, students may need to use external hard drives or require high bandwidth internet access to download them. Cloud computing can be a solution; however, the requirement of high bandwidth and storage capacity is a great challenge.

P2P communications use the next-generation high-speed (e.g. $10 \mathrm{Gbps}$ ) WiFi capable of reducing traffic loads [4] for sharing contents among users. WiFi has been one of the key contributing factors to the expansion of smart devices, and it has been a compulsory communication module for every device. For example, not only have smart phones, tablets, and digital cameras been equipped with WiFi, but also Secure Digital (SD) cards which are ultra small flash memory card. 
P2P between devices enables users to share e-Textbook contents without the need of a server, and so it reduces traffic loads in the network, particularly traffics accessing the server. In this work, we requested the interviewees about their opinions on how P2P between devices can be applied to improve service reliability. In our future work, P2P will be incorporated into our prototype to verify this.

\section{Addressing the Challenge of Improving Service Reliability}

Although cloud computing has great potential for data synchronization, in which users share data with other devices through "multiple copies of a dataset in coherence with one another" [47], and content sharing between devices, using cloud computing is more time consuming than using WiFi. Hence, P2P communications backed by WiFi infrastructure can improve the effectiveness of N-Screen service, and it can reduce traffic loads caused by data synchronization and content sharing in cloud computing [4].

Hence, P2P between devices can be a potential solution to overcome the challenge of improving service reliability in e-Textbooks implementation. For example, students can easily share their notes with others through P2P communications. Video content can also be shared with others through email, website, Learning Management System (LMS) and blog using P2P communications.

Selected comments received from the expert interview are as follows:

- P2P among two or more devices help to overcome challenges associated with sharing various contents over the internet because P2P enables direct connection [Expert2]

- P2P increases service reliability in the event of failure or disaster. [Expert8]

\section{CONCLUSIONS AND FUTURE WORK}

The objective of this article is to highlight the challenges and their potential solutions associated with e-Textbooks in the pursuit of replacing the traditional paper-based textbooks with e-Textbooks. Four major challenges are investigated, namely standardising format of contents, improving service reliability, improving quality and accuracy of content, as well as improving readability. This paper reviews technologies that offer solutions to address the challenges. We raise our research question "What are the technological solutions to the four challenges relevant to the development and distribution of e-Textbooks?"; and answer the question using our proposed technological solutions, which presents new technologies, including cloud computing, open market place, N-Screen services, HTML5 and P2P between screens, have been identified as potential solutions to overcome those challenges.

"The potentiality of e-Textbooks to reform education should not be underestimated" [27] and so the challenges related to the adoption of e-Textbooks raised in this article shall be addressed following the suggested technical solutions. The findings of this study provide guidance for subsequent research dealing with e-Textbook development and usage. Various problems and challenges associated with e-Textbook implementation in education system, including hardware, software, interface, management and social problems, can also be identified. Another potential future work is to develop a usage scenario in which people can use Google Apps and Office365 through e-Textbooks to provide a 
ubiquitous platform for collaborative learning among students.

\section{REFERENCES}

[1] ACM. "ACM Online Library," 5 June 2013; http://dl.acm.org/.

[2] Barker, P., " Designing Interactive Learning Systems " in Education and Training Technology International, 1990, pp. 125-150.

[3] Bates, A. W., Technology, Distributed Learning and Distance Education: Routledge, 2005.

[4] Bogotobogo. "N-Screen Connected Devices 2012 Anywhere, Anytime, Any device and Cloud " 18 Sep 2012; http://www.bogotobogo.com/WebTechnologies/nscreen_connected_devices.php.

[5] Boorsok, T., and Higginbothan-Wheat, N., "Interactivity: What is it and What Can it do for Computer-Based Instruction," Educ. Technol, pp. 11-17, 1991.

[6] Brady, A., "BYOD (Bring Your Own Device) and the Classroom," 1 Oct 2012, 2012.

[7] Brumley, M., "Don't be scared of Bring Your Own Device " Digital Learning Environment Blogs, 1 Oct 2012, 2012.

[8] Catone, J. "Digital Textbooks: 3 Reasons Students Aren't Ready," 1 Dec 2011, 2011; http://mashable.com/2009/08/17/digital-textbooks/.

[9] Clayton, M. J., "Delphi: a technique to harness expert opinion for critical decision making tasks in education," Educational Psychology, vol. 17, no. 4, pp. 373-386, 1997.

[10] Dictionary.com. "compatible," 6 June 2013; http://dictionary.reference.com/browse/compatible.

[11] DotComBlog. "Mobile application development," 29 Sept 2012, 2012; http://dotcomegypt.com/blog/?p=131.

[12] Elsevier. 5 June 2013; http://www.sciencedirect.com/.

[13] Emery, S., Factors for Consideration when Developing a Bring Your Own Device (BYOD) Strategy in Higher Education, University of Oregon, 2012.

[14] Facebook Developers. "HTML5," 6 Nov 2012; http://developers.facebook.com/html5/overview/.

[15] Google. "Google Apps for Business," 5 June 2013; http://www.google.com/enterprise/apps/business/products.html.

[16] Haddad, W. D., Green, A., Green, S. et al. "ICT-in-Education Toolkit," 31 March, 2010; http://ictinedtoolkit.org.

[17] Hardenburgh, I. "Google Apps v. Office 365: Head-to-head comparison of features," 5 June 2013; http://www.techrepublic.com/blog/datacenter/google-apps-voffice-365-head-to-head-comparison-of-features/5516.

[18] IEEE. "IEEE Xplore," 5 June 2013; http://ieeexplore.ieee.org/Xplore/home.jsp.

[19] IMSReseaerch. "Internet Connected Devices About to Pass the 5 Billion Milestone," $21 \quad$ Sep 2012; http://imsresearch.com/news-events/press-template.php?pr_id=1532.

[20] Ipadacademy. 22 Feb 2011, 2011; http://ipadacademy.com/2010/09/university-ofadelaide-will-replace-science-textbooks-with-ipads.

[21] ITEX. "International Invention Innovation \& Technology Exhibition "; 
http://www.itex.com.my/.

[22] Jobs, S. "Thoughts on Flash," 20 Sep 2012; http://www.apple.com/hotnews/thoughts-on-flash/.

[23] Kapp, K. M. "E-Learning Readiness Assessment Questions," 3 June, 2012; http://www.karlkapp.com/questions.pdf.

[24] Kim, R. "Multi-screen mania: how our devices work together," 18 Sep 2012; http://gigaom.com/2012/08/29/multi-screen-mania-how-our-devices-work-together/.

[25] Lee, H. J., "Educational policy and planning for Future Education Development of e-Textbooks," School of Information Technology Monash University, 2012.

[26] Lee, H. J., Messom, C., and Yau, K.-L. A., "The three types of e-Textbooks with their characteristics and open issues," Journal of Computing, vol. 4, no. 9, 2012.

[27] Lee, H. J., Messom, C., and Yau, K.-L. A., "Can electronic textbooks be part of K12 education?: Challenges, technological solutions and open issues," The Turkish Online Journal of Educational Technology, vol. 12, no. 2, 2013.

[28] McFall, R., Dershem, H., and Davis, D., "Experiences Using a Collaborative Electronic Textbook:Bringing the "Guide on the Side" Home With You," in SIGCSE'06, 2006.

[29] Mehrens, W. A., and Lehmann, I. J., Using standardized tests in education: Longman Publishing Group, 1987.

[30] Mercieca, P., "E-book acceptance: What will make users read on screen? ," in VALA 2004 Breaking Boundaries: Integration and Interoperability, Melbourne, Australia 2004, pp. 1-11.

[31] Miao, J.-y., Liu, C.-y., and Sun, Z.-h., "Study on the Method of the Technology Forecasting Based on Conjoint Analysis " Information Systems Development pp. 425-435, 2011.

[32] Microsoft. "Office 365," 5 June 2013; http://office.microsoft.com/.

[33] MSC Malaysia APICTA. "The Asia Pacific ICT Awards," http://www.mscapicta.com.my.

[34] Mudge, J. "Native App vs. Mobile Web App: A Quick Comparison," 6 June 2013; http://sixrevisions.com/mobile/native-app-vs-mobile-web-app-comparison/.

[35] NIST, "The NIST Definition of Cloud Computing," http://pre-developer.att.com/home/learn/enablingtechnologies/The_NIST_Definition_of_Cloud_Computing.pdf, [27 March 2013, 2011].

[36] Noorhidawatir, A., "A Study into usability of tools for searching and browsing ebooks with particular reference to back-of-the-book index," University of Strathclyde, 2007.

[37] Ozsoyoglu, G., Balkir, N. H., Ozsoyoglu, Z. M. et al., “On Automated Lesson Construction from Electronic Textbooks," IEEE Transactions on Knowledge and Data Engineering, vol. 16, no. 3, pp. 317-331, Mar, 2004.

[38] Patowary, K. "Test Your Document's Readability in Microsoft Word," 7 Oct 2012; http://www.instantfundas.com/2011/09/test-your-document-readability-in.html.

[39] Pocatilu, P., "Using WiMAX Technology for E-Learning Solutions," Oeconomics of Knowledge, vol. 2, no. 3, pp. Pp 6-10, 2010.

[40] ROA Holdings, N Screen \& Multi-Device Business Trends in the Japanese Market, 
2011.

[41] Robinson, S., "Student use of a free online textbook," Academy of Educational Leadership Journal, vol. 15, no. 3, 2011.

[42] Sadon, R., and Yamshon, L., "The State of the E-Textbook" PCWorld, 2011.

[43] Torterella, M., Mills, C., and Menko, A. "Service Reliability," 1 June 2013; http://committees.comsoc.org/cqr/FAE_Docs/A2_Srvc_Rel/sv2reliab.html.

[44] Vassiliou, M., "Progressing the definition of "e-book"," Library Hi Tech, vol. 26, no. 3, pp. pp355-368, 2008.

[45] Warschauer, M., Learning in the Cloud: How (and Why) to Transform Schools with Digital Media, New York: Teachers College Press, 2011.

[46] Webopedia. "cross-platform," 26/5/2013; http://www.webopedia.com/TERM/C/cross_platform.html.

[47] Wikipedia. "Synchronization (computer science)," 29 May 2013; http://en.wikipedia.org/wiki/Synchronization_(computer_science).

[48] Worthen, B. R., Borg, W. R., and White, K. R., Measurement and evaluation in the school: Longman Publishing Group, 1993.

[49] Yoon, C., Lee, H., and Ryu, W., "Classification of N-Screen Services, Scenarios and its Standardization," ICACT, 2013.

[50] Zadoks, R., and Ratner, J., "Developing Electronic Textbooks," http://www.osti.gov/bridge/servlets/purl/206888-MMip4Y/webviewable/206888.pdf, [25 Sep 2012, 1996]. 